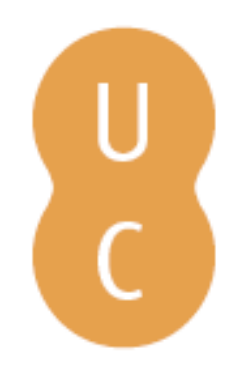

\title{
nombalina
}

\section{A capacidade de aprendizagem ao longo da vida e o bem-estar dos adultos em processo de RVCC de nível secundário}

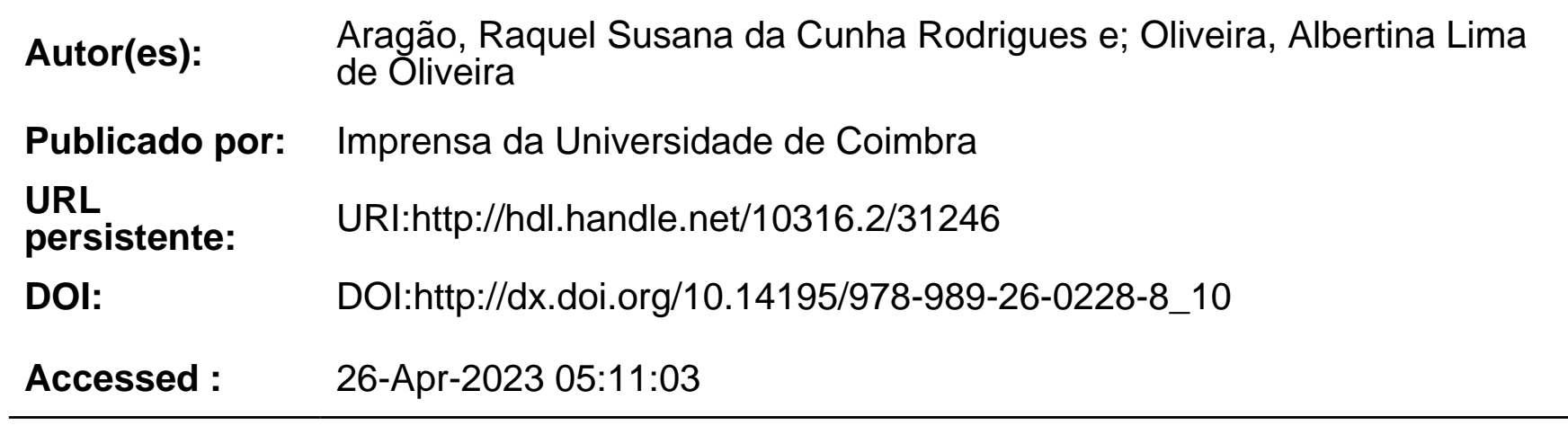

A navegação consulta e descarregamento dos títulos inseridos nas Bibliotecas Digitais UC Digitalis, UC Pombalina e UC Impactum, pressupõem a aceitação plena e sem reservas dos Termos e Condições de Uso destas Bibliotecas Digitais, disponíveis em https://digitalis.uc.pt/pt-pt/termos.

Conforme exposto nos referidos Termos e Condições de Uso, o descarregamento de títulos de acesso restrito requer uma licença válida de autorização devendo o utilizador aceder ao(s) documento(s) a partir de um endereço de IP da instituição detentora da supramencionada licença.

Ao utilizador é apenas permitido o descarregamento para uso pessoal, pelo que o emprego do(s) título(s) descarregado(s) para outro fim, designadamente comercial, carece de autorização do respetivo autor ou editor da obra.

Na medida em que todas as obras da UC Digitalis se encontram protegidas pelo Código do Direito de Autor e Direitos Conexos e demais legislação aplicável, toda a cópia, parcial ou total, deste documento, nos casos em que é legalmente admitida, deverá conter ou fazer-se acompanhar por este aviso.

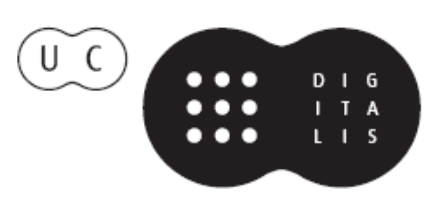




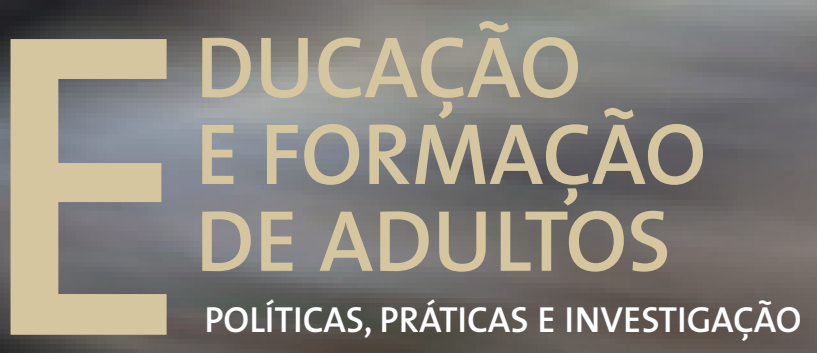

Luís Alcoforado • Joaquim Armando G. Ferreira António Gomes Ferreira • Margarida Pedroso de Lima Cristina Vieira • Albertina L. Oliveira • Sónia Mairos Ferreira 


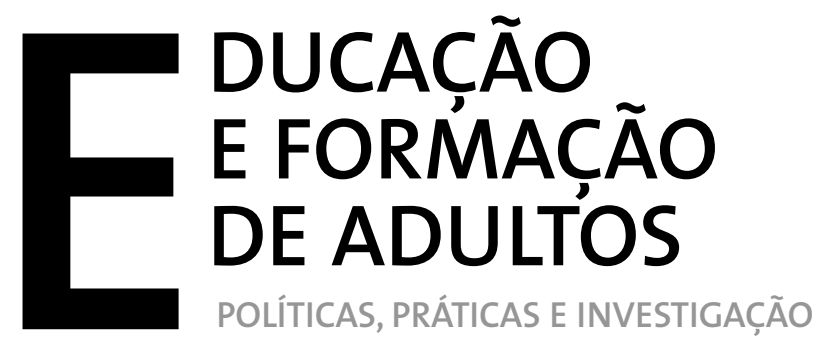

Luís Alcoforado • Joaquim Armando G. Ferreira António Gomes Ferreira - Margarida Pedroso de Lima Cristina Vieira • Albertina L. Oliveira • Sónia Mairos Ferreira 
EDIÇÃo

Imprensa da Universidade de Coimbra

URL: http://www.uc.pt/imprensa_uc

Vendas online: http://www.livrariadaimprensa.com

CONCEPÇÃO GRÁFICA

António Barros

Pré-Impressáo

SerSilito-Empresa Gráfica, Lda

EXECUÇÃo GRÁFICA

SerSilito-Empresa Gráfica, Lda

ISBN

978-989-26-0136-6

DePósito LEgaL

$340309 / 12$ 



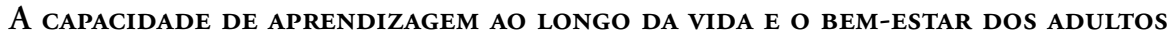 em PRocesso de RVCC de Nível SeCundário
}

\author{
Raquel Susana da Cunha Rodrigues e Aragáo \\ Albertina Lima de Oliveira \\ Universidade de Coimbra
}

\section{Introduçâo}

A implementação do actual Sistema Nacional de Reconhecimento, Validação e Certificação de Competências (RVCC) é resultado de uma evolução nas linhas orientadoras que definem a educação de adultos em Portugal e que se concretizaram na implementação de práticas diversas e complexas. Foi sobretudo a partir dos anos 60 do século passado que a educação de adultos ganhou um lugar de destaque nas prioridades políticas dos vários governos tendo, até à actualidade, sido implementadas várias práticas e criados vários mecanismos para os regular, dos quais poderemos destacar o Plano Nacional de Alfabetização e Educação de Base de Adultos (PNAEBA), a Lei de Bases do Sistema Educativo e a criação da Agência Nacional para a Educação e Formação de Adultos (ANEFA) (Pinho, Lobo e Caramujo, 1996; Lima, 2007).

No prosseguimento dos objectivos que foram definidos para a ANEFA, e com base no princípio de que a aprendizagem não se limita aos contextos de educaçáo formal e "a certeza de que os conhecimentos e saberes que as pessoas possuem estão muito aquém do que se encontra formalmente certificado", criou-se em Portugal um novo modelo de educação e formação de adultos (DGFV, 2004, p. 53). Foi para operacionalizar esse princípio, que a ANEFA criou gradualmente um Sistema Nacional de Reconhecimento, Validaçáo e Certificação de Competências.

O Sistema Nacional de RVCC consiste num modelo que se inscreve nos objectivos europeus para a educação e formação ao longo da vida, respondendo às orientaçóes e directrizes comunitárias, nomeadamente aquelas resultantes do Conselho Europeu de Lisboa ${ }^{1}$ (2000), do Memorandum sobre a Aprendizagem ao Longo da Vida ${ }^{2}$, do Conselho Europeu de Barcelona (2002) $)^{3}$, do Conselho Europeu de Dublin $(2004)^{4}$, e do relatório produzido

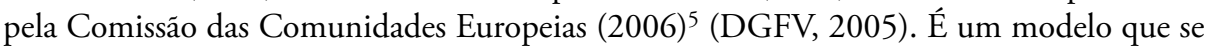
assume como uma "importante estratégia de implementação das políticas de aprendizagem ao longo da vida, da empregabilidade activa e da equidade social” (Almeida et al. 2008,

1 Neste Conselho foram enunciadas algumas prioridades para a política europeia do emprego, nomeadamente a redução das lacunas de formaçáo, a valorização da aprendizagem ao longo da vida e a promoção da igualdade de oportunidades.

2 Define a estratégia para a aprendizagem ao longo da vida na Europa.

3 Reforça a estratégia europeia para o emprego, acentuando a importância da aprendizagem ao longo da vida enquanto estratégia de promoção da empregabilidade.

4 Apresenta os "Princípios comuns europeus de identificação e validação da aprendizagem não formal e informal".

5 Apresenta cinco mensagens-chave para os intervenientes em educação de adultos, destacando o contributo essencial da educação de adultos para a empregabilidade e mobilidade num mercado de trabalho moderno, assim como para a inclusão social. 
p. 9). Se considerarmos que as mudanças sociais, científicas, tecnológicas e económicas da sociedade contemporânea são cada vez mais acentuadas e que essas mudanças implicam que, em permanência, se desenvolvam novos conhecimentos e competências, compreendemos os motivos subjacentes à emergência deste sistema (Oliveira, 2005). De facto, muitos deles são adquiridos à margem dos sistemas formais de educação e formação, não deixando por isso de serem provenientes de uma fonte legítima e com valor formativo (Pires, 2007).

A implementação deste modelo foi operacionalizada através da criação dos Centros de Reconhecimento, Validação e Certificação de Competências (CRVCC), os quais passaram a assumir uma perspectiva de desenvolvimento e aprendizagem ao longo da vida, destinandose a adultos (maiores de 18 anos) que pretendessem ver reconhecidas as suas competências, adquiridas por vias não formais e informais de aprendizagem (associadas à diversidade de experiências de vida), as quais são susceptíveis de uma certificação equivalente aos $4^{\circ}, 6^{\circ}$, $9^{\circ} \mathrm{ou}$, mais recentemente, $12^{\circ}$ ano de escolaridade.

A missão do Sistema Nacional de RVCC é, deste modo, reconhecer que determinado adulto possui certas competências, independentemente do lugar, tempo e forma como as adquiriu, validar essas competências, atribuindo-lhes uma validade social, escolar, profissional e legal e certificá-las, através da atribuição de um certificado equivalente ao da educação formal (Trigo, 2002). Assim, podemos identificar três eixos estruturantes deste sistema:

a) Eixo do Reconhecimento - Assenta no auto-reconhecimento das competências que o adulto desenvolveu através de diferentes contextos de aprendizagem, proporcionando momentos de exploração, identificação e avaliação dos saberes e competências adquiridos ao longo da vida.

b) Eixo da Validação - Consiste num conjunto de actividades/sessóes que visam apoiar o adulto no processo de avaliação das competências evidenciadas, face a um referencial de competências-chave, identificando-se as competências a validar (Gomes et al., 2007).

c) Eixo da Certificação - Corresponde à fase final do processo de RVCC, que consiste na confirmação oficial e formal das competências adquiridas pela via da experiência ao longo da vida, através da emissão de um diploma e/ou certificado de qualificaçóes ${ }^{6}$ (de nível básico ou nível secundário) (Portaria 86/2007).

Com base no que foi referido, podemos afirmar que o Sistema Nacional de RVCC, através do reconhecimento e validação das aprendizagens não formais e informais, se assume como um sistema de elevada importância no campo da educação e formação de adultos e constitui "a pedra angular da estratégia da aprendizagem ao longo da vida" (Comissão Europeia, 2006, p. 8) norteando-se, em Portugal, pelos valores e princípios do desenvolvimento pessoal, da coesáo e do reforço da participação social e do aprofundamento da cidadania.

Actualmente o Sistema Nacional de RVCC está integrado nos Centros Novas Oportunidades $(\mathrm{CNO})$, que são centros que assumem um papel central no encaminhamento dos adultos para qualquer oferta de qualificação escolar e profissional, nomeadamente para o acesso aos processos de RVCC. Em termos gerais, podemos identificar duas actividades

6 É emitido apenas um certificado de qualificaçôes sempre que o processo de RVCC não conduza à emissão de um diploma, i.e., sempre que o adulto não demonstre e valide todas as competências de nível básico ou de nível secundário, contempladas nos referenciais de competências-chave e necessárias para a certificação dos respectivos níveis de ensino. 
fundamentais destes centros: a) acolhimento, diagnóstico e encaminhamento dos candidatos inscritos para um percurso de qualificação; e b) realização de processos de reconhecimento, validaçáo e certificação de competências de nível básico (B1, B2 ou B3, correspondentes ao $4^{\circ}, 6^{\circ}$ ou $9^{\circ}$ ano de escolaridade), de nível secundário ${ }^{7}$ (correspondente ao $12^{\circ}$ ano) ou profissionais (conferindo uma qualificação de nível 2 ou 4).

O nosso estudo centrou-se na segunda actividade destes centros: a realização de processos de reconhecimento, validaçáo e certificação de competências, tendo incidido nos processos de nível secundário. De seguida iremos deter-nos na clarificação das orientaçóes teórico-metodológicas que estão subjacentes a estes processos.

\section{Matriz Conceptual de Operacionalizaçáo dos processos de RVCC-NS}

De uma forma genérica, o processo de RVCC organiza-se em torno de um conjunto de princípios da educação de adultos e de aspectos metodológicos específicos que permitem a demonstração de saberes e competências adquiridas ao longo da vida, através da construção de um Portefólio Reflexivo de Aprendizagens (PRA) ${ }^{8}$, à luz de um referencial de competências-chave.

Estes processos baseiam-se em princípios inovadores, que partem das experiências de vida dos adultos, desenvolvendo-se ao ritmo de cada um e contribuindo para consolidar percursos de auto-aprendizagem, reflexividade pessoal e formação individual (Gomes et al., 2006). Traduzindo o princípio da personalização dos processos formativos, pretende-se assim que seja um processo individualizado e que decorra ao ritmo de cada adulto.

O processo de RVCC-NS procura, através de um processo reflexivo, olhar para essas experiências e (re)elaborá-las, (re)avaliá-las e projectá-las na realidade presente e futura (Pires, 2007). Como afirma a equipa da DGFV (2004), "as metodologias de reconhecimento de adquiridos implementadas nos centros RVCC implicam um vaivém constante entre passado, presente e futuro e é, precisamente, ao reflectir sobre as experiências que vivenciaram (no passado) que as pessoas têm maior consciência do que são (no presente) e do que podem vir a ser (no futuro)" (p. 55). Na opiniáo desta equipa, este poderá ser um processo (auto)formativo e (trans)formativo, que potencia o auto-conhecimento, nomeadamente no que ao reconhecimento das suas próprias competências diz respeito. Será esta tomada de consciência de si próprio que poderá induzir a (trans)formação do sujeito e, consequentemente, do mundo que o rodeia.

A matriz conceptual do processo de RVCC-NS, nomeadamente no eixo do reconhecimento de competências, no que aos elementos metodológicos diz respeito, baseia-se

\footnotetext{
7 Os processos de RVCC-NS destinam-se a adultos maiores de 23 anos que não concluíram o ensino secundário, ou a adultos (maiores de 18 anos) com idade inferior a 23 anos, mas detentores de 3 anos de experiência profissional (no caso do adulto ter idade inferior a 23 anos, a experiência profissional tem de ser devidamente comprovada).

8 "Um portefólio pode ser encarado como uma derivação de um dossiê, sendo que os distingue o facto de em termos de filosofia de avaliação de ensino/aprendizagem, o dossiê representar «uma racionalidade, redutora simplista, de cariz tecnicista e instrumental» enquanto que o paradigma que está subjacente à utilização de um portefólio é o de uma filosofia de aprendizagem, baseada num processo de «investigação/acção/formação". Supõe o desenvolvimento de um perfil de competências meta-cognitivas e meta-reflexivas, sobre o próprio conhecimento, que nele se procura evidenciar" (Gomes et al., 2006, p. 36).
} 
nos seguintes três: a abordagem autobiográfica, o balanço de competências e o portefólio reflexivo de aprendizagens, os quais são conduzidos com base numa matriz orientadora - o Referencial de Competências-Chave de Nível Secundário (RCC-NS).

116 a) Referencial de Competências-Chave de Nivel Secundário

O RCC-NS constitui-se como um quadro orientador e estruturador para o desenvolvimento dos processos de RVCC de Nível Secundário. É o instrumento face ao qual se avaliam as competências-chave adquiridas pelos adultos, em diferentes contextos de vida, com vista à atribuição de uma certificação. Para além disso, ele também opera como "uma matriz integradora entre o reconhecimento e a validação das competências de que os adultos são portadores e o desenvolvimento de percursos formativos adequados às necessidades pessoais, sociais e profissionais que manifestam" (Gomes et al., 2006, p. 94). O RCC-NS organiza-se em torno de três áreas de competências-chave: Sociedade, Tecnologia e Ciência (STC); Cultura, Língua e Comunicação (CLC) e Cidadania e Profissionalidade (CP).

\section{b) Abordagem Autobiográfica}

O reconhecimento, validação e certificação de competências de nível secundário recorre à abordagem autobiográfica como meio de recolha de informação, procurando apelar a uma interrogação permanente e à atribuição de sentido às experiências vividas (Gomes et al., 2006, p. 29). Essa metodologia, de acordo com Josso (2002), é formativa e mobiliza um trabalho de reflexividade sobre a identidade, necessidades, escolhas, decisóes e sobre as próprias ideias do adulto, a qual, em conjunto com a história de vida, permite encontrar uma nova maneira de pensar a relação dos adultos com o saber e com o conhecimento. A abordagem autobiográfica assume assim um valor heurístico de auto e hetero-descoberta, permitindo ao adulto identificar experiências relevantes, vivenciadas nas diferentes esferas da sua vida, numa dimensão espácio-temporal, e re-significá-las, favorecendo uma melhor capacidade de compreensão sobre si e sobre a relação com o outro (Gomes et al., 2006). Esta metodologia, ao implicar que o adulto repense o sentido atribuído às suas experiências de vida, exige uma articulação entre os processos de natureza racional do adulto e outros que se prendem com a sua imaginação. Como afirma Josso (2001), "nas histórias de vida o racional e o emocional encontram-se intrinsecamente associados. A linguagem utilizada na sua interpretação é racional; contudo, a interpretação das histórias apela ao criativo, ao sentido atribuído e, por isso, à imaginação e à (re)descoberta do passado à luz do presente e do futuro. Os elementos biográficos são organizados segundo elos de ligaçáo entre os diferentes momentos temporais e vivenciais" (p. 191).

\section{c) Balanço de Competências}

A metodologia de Balanço de Competências, no contexto dos processos de RVCC-NS, constitui-se como um processo de reflexão pessoal do adulto sobre as suas potencialidades e fragilidades, permitindo o seu posicionamento face a projectos futuros mas que deve ser orientado em função do Referencial de Competências-Chave de Nível Secundário, enquanto matriz orientadora para o posicionamento dessas competências. Tendo em vista o tema do nosso estudo, esta metodologia reveste-se de uma importância fundamental, pois baseiase na introspecção e reflexão e faz emergir uma representação de si em várias dimensóes. Permite perspectivar as várias mudanças operadas nos sujeitos e apoia a exploração de si próprio, o que se revela de uma grande centralidade na influência que proporciona nas várias dimensóes pessoais que iremos estudar. 


\section{d) Portefólio Reflexivo de Aprendizagens}

O PRA é um documento que se articula e decorre do Balanço de Competências, pois permite que o adulto reflicta e tenha, ele próprio, noção das suas competências e dos momentos/situaçóes da sua vida em que as mobiliza (Gomes et al., 2006), baseando-se numa narrativa múltipla, de natureza biográfica, "que se situa nas relaçóes entre o aprender e o viver, enquanto construçáo social das suas histórias de vida” (Luwisch, cit. por Gomes et al., 2006, p. 38).

O PRA é assim entendido como a concretização da tomada de consciência da história de vida (abordagem autobiográfica) e do balanço de competências. Considerando que o PRA consiste na reuniáo de vários documentos, que revelam o desenvolvimento e progresso da aprendizagem, sob uma perspectiva de auto-reflexão e reconstruçáo das experiências de vida, identificando as competências adquiridas ao longo da mesma, compreendemos que o mesmo se encontra estritamente ligado à metodologia de Balanço de Competências e à de História de Vida, que se estabelecem como os elementos estruturantes da construção do portefólio.

Em jeito de conclusão, podemos referir que o processo de RVCC-NS assenta numa metodologia de Balanço de Competências, através da qual o adulto é apoiado na exploração da sua História de Vida, mediante a construção de um Portefólio Reflexivo de Aprendizagens, procurando, de forma integrada e através dos vários temas desenvolvidos no seu PRA, evidenciar as competências constantes no Referencial de Competências-Chave de Nível Secundário, possibilitando, assim, uma certificação de Nível Secundário, através da via da experiência de vida. Estas metodologias são ricas na exploração dos significados que são atribuídos à própria experiência e permitem uma resignificação da mesma, com vista à mudança e ao desenvolvimento pessoal. Daí se depreende a sua importância para a presente investigação, pois é o desenvolvimento destas metodologias que se supóe promover alteraçôes em algumas variáveis psicológicas, subjacentes a dimensôes de mudança pessoal, que nos propusemos estudar.

Assim, com este estudo, pretendemos estudar os factores que são susceptíveis à mudança, através do processo de RVCC-NS, os quais se situam, sobretudo, na esfera das mudanças pessoais. Tendo por base a conceptualização e operacionalização do processo de RVCC-NS, bem como os estudos já efectuados sobre o mesmo, parece-nos ser de esperar que a capacidade para autodirigir a aprendizagem aumente, bem como a autoconfiança dos adultos para este mesmo tipo de aprendizagem e a sua percepção de competência cognitiva. Correlativamente, mas ligado a dimensóes de mudança no bem-estar pessoal, e igualmente na sequência dos resultados de alguns estudos (e.g., Oliveira, 2005), a auto-estima e a satisfação com a vida também foram tidas em consideração e igualmente se espera que aumentem.

\section{Dimensóes de mudança pessoal no processo de RVCC-NS}

No presente estudo, a aprendizagem autodirigida é entendida enquanto fenómeno em que o educando detém iniciativa e possuiu a responsabilidade principal pela sua aprendizagem. Apesar da autodirecçáo na aprendizagem ser um fenómeno complexo, que tem sido estudado sob diferentes perspectivas (resultando em diferentes concepçóes neste campo), existe um consenso substancial em considerar-se que é um constructo multidimensional e 
que integra três dimensóes: psicológica (ou pessoal), pedagógica e social (Oliveira, 2005). $\mathrm{Na}$ opinião de Oliveira (2005), estas três dimensões encontram-se interligadas por uma espiral, representativa do "movimento dialéctico de progressão do indivíduo, que tem o seu início com o irromper da vida e que se vai expandindo à medida que ele, em interacção com o ambiente ou os contextos de vida, se torna cada vez mais capaz de se autodirigir, participando em projectos pessoal e socialmente significativos e enriquecedores" (p. 99).

Através de uma análise da autodirectividade nos adultos, tendo por referência o modelo andragógico de Knowles, é de esperar que os adultos apresentem diferentes níveis de autonomia, bem como diferentes níveis de autodirecção na aprendizagem, pois apesar do modelo pressupor uma evolução de um estado de dependência (na infância) para uma crescente autodirectividade (na adultez), este processo não ocorre de forma linear, podendo verificar-se que muitos adultos náo desenvolvem a sua autodirectividade tanto quanto seria desejável, muito embora a sociedade contemporânea exija, cada vez mais, estas competências aos adultos (Knowles, 1998).

A aprendizagem autodirigida reveste-se, assim, de inúmeras potencialidades. Na opinião de Nyhan (1996, cit. por Santos, 1999), "a competência de auto-aprendizagem permite às pessoas uma aprendizagem activa numa variedade de situaçóes ao longo de toda a sua vida, fazendo com que tomem consciência e adoptem uma atitude aberta relativamente às oportunidades de aprendizagem nas suas experiências quotidianas [...e encarem] a aprendizagem como um acontecimento natural de todos os dias, sendo capazes de explorar as oportunidades de aprendizagem que surgem no local de trabalho, de utilizar de modo eficaz as experiências de ensino formais e estruturadas, bem como os sistemas de transmissão multimédia e de aprendizagem aberta” (p. 59).

Veiga Simáo et al. (2006), com base nos estudos realizados sobre esta temática, sintetizaram algumas características reveladas pelos sujeitos que auto-regulam a aprendizagem. De entre estas, e tendo em conta o objecto de estudo desta investigação, parece-nos importante salientar que os mesmos: a) manifestam capacidade para planificar, controlar e dirigir os seus processos mentais para a concretizaçáo de metas pessoais; b) demonstram crenças motivacionais e emocionais adaptativas (e.g., elevado conceito de auto-eficácia escolar; estabelecimento de metas de aprendizagem); c) evidenciam competências para gerir o tempo e o esforço dedicado à realizaçáo de tarefas, bem como a capacidade para criar ambientes propícios para a aprendizagem e d) mobilizam estratégias que potenciam a concentração, o esforço e a motivação na realização de tarefas académicas. Muito embora o contexto acabado de referir seja predominantemente formal, todas estas características apresentam uma elevada adequaçáo face ao desenvolvimento do PRA, por parte dos adultos que realizam os processos de RVCC-NS.

\section{Objectivos do estudo}

O objectivo principal do nosso estudo consistiu em compreender até que ponto a realização do processo de RVCC-NS contribui para aumentar a capacidade de autoaprendizagem e o bem-estar pessoal dos sujeitos.

Para além deste objectivo geral, foram definidos os seguintes objectivos específicos:

1. Analisar a predisposição para a aprendizagem autodirigida e a auto-confiança para a auto-aprendizagem em adultos que realizaram o processo de RVCC-NS; 
2. Estabelecer uma relação entre a percepção pessoal de competência cognitiva e a realização do processo de RVCC-NS;

3. Identificar a realização do processo de RVCC-NS como um factor potenciador da auto-estima dos sujeitos;

4. Identificar se existe uma relação entre a satisfação com a vida e a realização do processo de RVCC-NS.

\section{Metodologia}

Para testarmos as hipóteses resultantes dos nossos objectivos e na impossibilidade, por razóes que se prenderam com constrangimentos de tempo, éticos e socio-políticos, de realizarmos um estudo experimental, optámos por um plano de investigação não experimental comparativo-causal, uma vez que não houve qualquer tipo de manipulação da variável independente no decorrer do nosso estudo.

De entre os vários planos não experimentais, recorremos ao desenho Ex Post Facto, uma vez que o nosso estudo pretendia examinar os "efeitos de um tratamento que ocorreu naturalmente, depois do mesmo se ter verificado" (Tuckman, 2002, p. 236), procurando relacionar o tratamento com hipotéticos resultados (variáveis dependentes definidas no nosso estudo). Sendo ainda mais precisos, utilizámos um desenho com grupo de critério ${ }^{9}$, uma vez que o nosso objectivo foi estabelecer uma relação entre a realização de um processo de Reconhecimento, Validação e Certificação de Competências de Nível Secundário e a não realização do mesmo nas variáveis atrás referidas. Desta forma, foram constituídos dois grupos: os adultos que concluíram o processo de RVCC-NS (grupo de critério) e adultos que não realizaram este processo (grupo de comparação), com o objectivo de os comparar nas variáveis dependentes.

Apesar de termos consciência de que se trata de um plano com limitaçóes, no que respeita ao grau de controlo de variáveis potencialmente parasita, interessou-nos verificar se existe relaçáo entre a variável independente e as variáveis dependentes do nosso estudo, permitindo-nos este desenho estabelecer essa associação. Como afirma Tuckman (2002), "embora seja muito difícil estabelecer relaçóes de causalidade, é possível identificar as causas potenciais, que poderáo vir a ser testadas, mais directamente pelo processo de manipulação" (p. 240).

\section{Instrumentos}

O protocolo de investigação aplicado era constituído por uma parte inicial destinada à apresentação sumária do estudo. Neste campo, pretendeu-se clarificar os objectivos da investigação, apelar à sinceridade nas respostas e assegurar o anonimato e confidencialidade de todos os dados. De seguida, foi criado um campo de dados pessoais, destinado ao registo de respostas relativas às variáveis sócio-demográficas (sexo, estado civil, idade, zona de residência, situação e experiência profissional, escolaridade, motivos de interrupção dos estudos e frequência de acções de formação).

\footnotetext{
9 Esta designação é apresentada por Tuckman (2002), sendo também conhecida por design comparativo-causal.
} 
A operacionalização das variáveis dependentes implicadas nesta investigaçáo levou a que o protocolo de investigaçáo ficasse constituído por cinco questionários. Relativamente à variável aprendizagem autodirigida, optámos pela Escala de Auto-Aprendizagem de Santos e Faria (1998). Associada a esta variável, utilizámos ainda o Questionário de Auto-Eficácia para a Aprendizagem Autodirigida (Bloyd, Hoban e Wall 1995, adaptação portuguesa de Oliveira \& Simóes, 2001). No que diz respeito à percepçáo de competência cognitiva, optámos pela Escala de Auto-Conceito de Competência Cognitiva de Räty e Snellman (1992, adaptação portuguesa de Faria e Santos, 1998). Para avaliar a auto-estima, optámos pela Escala de Auto-Estima de Rosenberg (1965, adaptação portuguesa de Simôes e Lima, 1992) e, por fim, para aferir a satisfação com a vida dos sujeitos da amostra, utilizámos a Escala de Satisfação com a Vida de Diener et al. (1985, adaptação portuguesa de Simóes, 1992).

A finalizar o protocolo, na última folha, pediu-se para os sujeitos reflectirem livremente sobre as principais mudanças que sentiram/experimentaram com o processo de RVCC.

\section{Procedimentos}

Dadas as características específicas dos sujeitos da nossa amostra, constituído o protocolo de investigação, realizámos um pequeno estudo preliminar, que teve por objectivo analisar se o protocolo era adequado, nomeadamente, para verificar se existiam dificuldades no preenchimento dos questionários e na compreensão dos seus itens, estimar a duraçáo necessária para o seu preenchimento e avaliar, em geral, a receptividade dos adultos ao protocolo. A realização deste estudo preliminar revelou-se uma mais-valia para a investigação definitiva. De forma genérica, a organização, sequência e estrutura do protocolo de investigação não revelou nenhuma dificuldade por parte dos sujeitos participantes.

A recolha de dados decorreu entre Dezembro de 2008 e Fevereiro de 2009. Nos questionários aplicados no Centro de Formação Profissional do Porto, a investigaçáo foi apresentada a todos os sujeitos participantes pela primeira autora e no Centro de Formação Profissional de Rio Meão, a apresentação do estudo coube a um Profissional de RVC ${ }^{10}$.

Em ambos os locais, a aplicação do questionário foi sempre precedida de uma apresentação do estudo, da clarificação das instruçóes de preenchimento e de algumas consideraçóes que entendemos serem fundamentais realçar oralmente (apesar das mesmas se encontrarem na introdução do protocolo de investigação) nomeadamente, o facto do preenchimento dos questionários ser de carácter voluntário, a recomendação de uma leitura atenta das instruçóes e de todos os itens, o apelo à sinceridade das respostas e o esclarecimento de que não existiam respostas certas ou erradas, mas apenas pontos de vista pessoais, reforçando a importância de não ser omitida nenhuma resposta.

A aplicação destes questionários, em regime presencial, foi uma mais-valia porque permitiu esclarecer todas as dúvidas, quer no que diz respeito à compreensão de alguns itens, quer no que diz respeito ao seu preenchimento.

\footnotetext{
${ }^{10}$ A recolha de dados no Centro de Formação Profissional de Rio Meão foi sempre conduzida pelo mesmo profissional, tendo sido realizada (para efeitos de preparação da mesma), previamente, uma reunião com a autora, que visou esclarecer como devia ser conduzida a apresentação da investigação. Neste sentido, foi entregue um guião com os aspectos que deveriam ser clarificados, procurando-se, assim, uniformizar a apresentação do protocolo de investigação, entre os sujeitos que integraram as amostras recolhidas nos dois centros.
} 
Deste modo, o processo de administração decorreu normalmente, sem problemas relevantes, sendo que verificámos, por parte de todos os participantes, uma grande abertura e vontade de colaborar no estudo, prontificando-se a responder ao protocolo de investigaçáo. No total foram realizados 11 momentos de aplicação do protocolo em ambos os centros, com uma duração média de 40 minutos cada.

\section{Amostra}

Em consonância com os objectivos do nosso estudo e com as hipóteses delineadas para o mesmo, definimos como população-alvo os adultos que haviam finalizado recentemente ${ }^{11} \mathrm{o}$ processo de RVCC de Nível Secundário na zona Norte do país. De entre os $\mathrm{CNO}$ existentes nesta zona, foram seleccionados o Centro de Formação Profissional do Porto e o Centro de Formação Profissional de Rio Meão. A opção por estes dois Centros de Formação/Centros Novas Oportunidades teve por base duas conjunturas. Em primeiro lugar, é importante considerar que os processos de RVCC de Nível Secundário são recentes, não havendo um leque muito vasto de adultos certificados que permitisse uma ampla recolha de dados. Neste sentido, a opção recaiu sobre o Centro de Formação Profissional do Porto (CFPP), uma vez que foi um dos centros pioneiros no arranque destes processos no distrito do Porto, motivo pelo qual apresentava um maior número de adultos certificados.

A segunda prende-se com a selecção do segundo centro (Centro de Formaçáo Profissional de Rio Meão - CFPRM), o qual foi escolhido por apresentar uma estrutura do processo de RVCC-NS muito idêntica ao CFPP. De facto, apesar das orientaçôes definidas pela ANQ, os $\mathrm{CNO}$ têm alguma liberdade na implementação das metodologias, nomeadamente, no número de sessóes colectivas e individuais e no número de sessóes com formadores e Profissionais de RVC. Pretendendo controlar estas variáveis, foi seleccionado o CFPRM, uma vez que estruturou o seu processo com base nas práticas do primeiro centro.

Assim, e no que respeita à amostra propriamente dita, participaram neste estudo 56 adultos inscritos para a realizaçáo do processo de RVCC-NS e 49 sujeitos que realizaram e concluíram o mesmo processo, tendo obtido a certificação total e, por isso, equivalente ao diploma de Nível Secundário. Todavia, pelas razóes que são clarificadas de seguida, a amostra final veio a incluir menos 14 sujeitos. A exclusão de sujeitos prendeu-se com as diferenças significativas encontradas entre as duas amostras em algumas variáveis sóciodemográficas ${ }^{12}$. Assim, procedeu-se à exclusão de 10 sujeitos no grupo A (sujeitos inscritos para o processo de RVCC-NS - grupo A) e de 4 no grupo B (sujeitos que concluíram o processo de RVCC-NS - grupo B), numa tentativa de tornar as amostras o mais equivalentes possível, permitindo assim um maior controlo de variáveis parasita. Desta forma, as amostras finais passaram a ser constituídas por 45 sujeitos em ambos os grupos.

A selecção dos sujeitos que fizeram parte destas amostras não foi aleatória, prendendose unicamente com a questão temporal de aplicaçáo do protocolo de investigação. Assim, fizeram parte desta investigação todos os sujeitos que foram encaminhados para processo

11 Os questionários foram aplicados durante o período de 15 dias após a certificação.

12 Foram encontradas diferenças significativas nas variáveis sócio-demográficas: sexo; escolaridade; idade e frequência de acçôes de formação. 
de RVCC e sujeitos que concluíram o processo de RVCC nos meses de Dezembro de 2008 e Janeiro e Fevereiro de 2009, nos dois Centros Novas Oportunidades acima referidos.

No total, a nossa amostra, no que concerne ao sexo, ficou constituída por 62 sujeitos do género masculino e 27 sujeitos do género feminino, encontrando-se distribuídos pelos dois grupos da seguinte forma: 28 sujeitos do sexo masculino e 16 sujeitos do sexo feminino $^{13}$ no Grupo A e 34 sujeitos do sexo masculino e 11 do sexo feminino no Grupo B.

Relativamente à idade, os participantes apresentavam idades compreendidas entre os 23 e os 63 anos $^{14}$, com um valor médio de 39 anos no Grupo A e de 41.47 anos no Grupo $\mathrm{B}$, sendo que, em ambas as amostras, a maioria dos sujeitos se encontrava na faixa etária dos 31 aos 50 anos.

No que diz respeito à situação profissional dos sujeitos deste estudo, verificou-se que a maioria deles se encontrava a trabalhar por conta de outrem (33 sujeitos no Grupo A e 32 sujeitos no Grupo B) e que apenas 25 sujeitos se encontravam noutra situação profissional. Entre estes últimos, a categoria mais representada foi a de desempregados, seguindo-se a de trabalhadores por conta própria e, por fim, a de reformado.

A análise do estado civil mostrou que a maioria dos sujeitos se encontrava casada, sendo que no total das amostras, apenas 28 sujeitos (do universo de 90) possuíam outro estado civil, sendo estas outras condiçóes muito semelhantes entre si.

No que diz respeito à escolaridade que os sujeitos possuíam antes de iniciarem o processo de RVCC, constatou-se que a maioria tinha o $9^{\circ}$ ano (58 nas duas amostras), verificando-se um reduzido número (em ambos os grupos) com escolaridade inferior, um número relativamente assimétrico no que diz respeito aos sujeitos que detinham o $10^{\circ}$ ano e o mesmo número de efectivos no que concerne ao $11^{\circ}$ ano de estudos.

Por último, a análise de frequência de acçôes de formação ao longo da vida por parte dos sujeitos implicados neste estudo ${ }^{15}$, mostrou-nos que a grande maioria (73 sujeitos) já havia realizado acçóes de formação previamente à realização/inscrição no processo de RVCC-NS. Consideramos ser esta uma variável fundamental, pois a realização de acçóes de formação é uma fonte de aprendizagem ao longo da vida, que proporciona a aquisição de novos conhecimentos e competências e, por isso, uma mais-valia para a realização de processos de reconhecimento, validaçáo e certificação de competências, bem como para o desenvolvimento cognitivo e pessoal dos sujeitos.

\section{Resultados}

Previamente às análises propriamente ditas, foram realizadas um conjunto de análises preliminares ${ }^{16}$.

${ }^{13}$ De referir que um dos sujeitos não indicou o género, motivo pelo qual a caracterização da amostra face ao género diz respeito apenas a 89 sujeitos.

14 De referir que um dos sujeitos náo indicou a idade.

15 De referir que 2 dos sujeitos não responderam a este item, motivo pelo qual a caracterização da amostra diz respeito a apenas 88 sujeitos.

${ }^{16}$ Numa primeira fase consistiram na detecção de erros de digitação e na recodificação dos itens invertidos. De entre os instrumentos de medida que foram aplicados, um deles incluía itens invertidos: a Escala de AutoEstima de Rosenberg (ROS). 
De seguida, apresentamos as estatísticas descritivas que sustentaram o estudo das hipóteses desta investigação.

Começando por nos referirmos às estatísticas descritivas das variáveis quantitativas, para além das análises relativas à normalidade das distribuições, já mencionadas, calculámos a média, a mediana, o desvio-padrão e os valores mínimos e máximos. Estas estatísticas encontram-se sintetizadas no quadro 1.

Quadro 1. Estatísticas descritivas das variáveis em estudo

\begin{tabular}{|c|c|c|c|c|c|c|c|}
\hline Variáveis & Grupo & $\mathbf{n}$ & Média & Mediana & $\begin{array}{l}\text { Desvio- } \\
\text { Padráo }\end{array}$ & Mínimo & Máximo \\
\hline \multirow{2}{*}{ SE-SDLQ } & Grupo A & 45 & 68,82 & 70,00 & 15,90 & 29,00 & 100,00 \\
\hline & Grupo B & 45 & 71,38 & 75,00 & 14,09 & 33,00 & 100,00 \\
\hline \multirow{2}{*}{ ROS } & Grupo A & 45 & 33,14 & 34,00 & 4,83 & 23,00 & 40,00 \\
\hline & Grupo B & 45 & 36,22 & 37,00 & 2,83 & 31,00 & 40,00 \\
\hline \multirow{2}{*}{ EAA } & Grupo A & 44 & 118,81 & 118,00 & 9,98 & 97,00 & 144,00 \\
\hline & Grupo B & 44 & 124,08 & 123,00 & 8,87 & 92,00 & 143,00 \\
\hline \multirow{2}{*}{ ACCC } & Grupo $A$ & 43 & 112,98 & 113,00 & 8,97 & 81,00 & 144,00 \\
\hline & Grupo B & 45 & 118,38 & 119,00 & 11,99 & 87,00 & 144,00 \\
\hline \multirow{2}{*}{ SWLS } & Grupo A & 45 & 14,96 & 15,00 & 4,87 & 7,00 & 25,00 \\
\hline & Grupo B & 45 & 18,13 & 18,00 & 4,57 & 5,00 & 25,00 \\
\hline
\end{tabular}

De seguida, procedemos à análise de cada questionário, a fim de verificarmos a frequência e distribuição de respostas omissas e procedermos à eliminação de casos que revelassem suspeitas nas suas respostas. Nos questionários dos sujeitos pertencentes ao Grupo A, foram encontrados valores omissos nos seguintes instrumentos: Escala de Auto-Estima (ROS); Escala Auto-Aprendizagem (EAA); Escala de Auto-Conceito de Competência Cognitiva (ACCC); e na Escala de Satisfação com a Vida (SWLS).

Nos questionários dos sujeitos integrados no Grupo B foram encontrados os seguintes missing values: Escala de Auto-Estima (ROS); Escala de Auto-Aprendizagem (EAA); Escala de Auto-Conceito de Competência Cognitiva (ACCC); Questionário da Autoeficácia para a Aprendizagem Autodirigida (SE-SDLQ); e na Escala de Satisfação com a Vida (SWLS).

Considerando que os valores omissos eram aleatórios, dado que náo nos pareceram revelar nenhum carácter sistemático, procedeu-se à sua substituição pela média aritmética do respectivo item, tal como é recomendado por Newton e Rudestam (1999). Assim, verificámos que, dos 105 questionários recolhidos, todos apresentavam condiçóes para serem utilizados no nosso estudo.

Posteriormente, analisámos a ocorrência de casos extremos univariados. Estes casos caracterizam-se por se situarem fora da amplitude habitualmente esperada para a variável em análise e podem ser classificados como moderados ou extremos, mediante a distância a que se encontram dos valores correspondentes ao primeiro e terceiro quartis da distribuição (Oliveira, 2005). Em primeiro lugar, começámos por analisar se existiam valores extremos em consequência de erros de digitação, procedendo à verificação dos respectivos protocolos e repondo o seu valor verdadeiro. De seguida, passámos a determinar o número de respostas extremas reais e, através da análise dos diagramas da caixa de bigodes, verificámos a existência de alguns casos moderados bem como de alguns casos extremos. Em concreto, verificámos que, na Escala de Auto-Aprendizagem (EAA), se encontravam vários casos moderados. Por esse motivo, procedemos à eliminaçáo dos dois casos mais extremos. Na Escala de Auto-Conceito de Competência Cognitiva (ACCC), foram encontrados dois casos extremos, pelo que procedemos, igualmente, à sua exclusão. No que diz respeito aos diagramas da caixa de bigodes relativos à Escala de Satisfaçäo com a Vida (SWLS) e ao Questionário de Auto-Eficácia para a Aprendizagem Autodirigida (SE-SDLQ), verificámos a existência de um caso moderado em cada um destes. No entanto, uma vez que eram casos moderados, encontrando-se bastante próximos do limite, não foram eliminados. No que diz respeito à Escala de Auto-Estima de Rosenberg (ROS) não se registou nenhum caso moderado ou extremo, prevalecendo uma condiçấo de normalidade da distribuição, o que reforça a ideia de equilíbrio dos dados nestas variáveis. 
Como podemos ver, através do quadro 1 , as médias do grupo B, em termos absolutos, são sempre mais elevadas que as do grupo A.

De seguida, antes de avançarmos para o teste das hipóteses, através de estudos diferenciais, procurámos avaliar a existência de diferenças significativas entre os dois grupos, verificando-se que as mesmas não existiam na variável autoconfiança para a aprendizagem autodirigida.

Uma vez que pretendemos comparar o comportamento de determinadas variáveis dependentes em dois grupos independentes, aplicámos o Teste de $t$ de Student. Assim, passamos a apresentar os resultados, em função de cada hipótese, testada através deste teste.

Uma das hipóteses afirmava que "Os adultos que realizaram o processo de RVCC-NS apresentam maior predisposiçâo para a auto-aprendizagem comparativamente a adultos que não o realizaram" - esta hipótese foi testada através da EAA, tendo sido confirmada (quadro 2).

Quadro 2. Teste t para a autodirecção na aprendizagem (EAA)

\begin{tabular}{llccccccc}
\hline \multicolumn{1}{c}{ EAA } \\
\hline $\begin{array}{c}\text { Identificaçáo do } \\
\text { Instrumento }\end{array}$ & $\begin{array}{c}\text { Identificaçáo } \\
\text { do Grupo }\end{array}$ & $\mathbf{N}$ & Média & Desvio-Padráo & $\boldsymbol{g l}$ & $\boldsymbol{t}$ & $\boldsymbol{p}$ \\
\hline \multirow{2}{*}{ EAA } & Grupo A & 44 & 118,81 & 9,98 & & 86 & $-2,620$ &, 010 \\
\cline { 2 - 6 } & Grupo B & 44 & 124,08 & 8,87 & & \\
\hline
\end{tabular}

$n$ - tamanho da amostra; $g l$ - graus de liberdade

Associada à hipótese anterior, testámos se " $A$ auto-confiança para a aprendizagem autodirigida dos adultos que realizaram o processo de RVCC-NS é significativamente superior à auto-confiança dos adultos que não o realizaram" - para testarmos esta hipótese, analisámos a diferença entre as duas amostras através dos resultados do SE-SDLQ. A hipótese não foi validada, pois o valor de $p$ revelou não ser significativo $(p=0,421)$, muito embora a tendência, em termos absolutos, se tenha verificado (quadro 3).

Quadro 3. Teste t para a auto-eficácia para a aprendizagem autodirigida (SE-SDLQ)

\begin{tabular}{|c|c|c|c|c|c|c|}
\hline \multicolumn{7}{|c|}{ SE-SDLQ } \\
\hline Identificaçáo do Grupo & $N$ & Média & $\begin{array}{l}\text { Desvio- } \\
\text { Padrão }\end{array}$ & $g l$ & $t$ & $p$ \\
\hline Grupo A & 45 & 68,82 & 15,90 & \multirow{2}{*}{88} & \multirow{2}{*}{,- 808} & \multirow{2}{*}{, 421} \\
\hline Grupo B & 45 & 71,38 & 14,09 & & & \\
\hline
\end{tabular}

$\mathrm{n}$ - tamanho da amostra; gl - graus de liberdade

Outra das hipóteses em estudo, a de que " $A$ percepção de competência cognitiva difere significativamente no grupo de sujeitos que realizaram o processo de RVCC em comparaçáo com o grupo que não o realizou", foi corroborada, uma vez que a média do grupo A revelou ser significativamente mais baixa que a do grupo $\mathrm{B}$, de acordo com os valores que se encontram apresentados no quadro 4. 
Quadro 4. Teste t para a percepção de competência cognitiva (ACCC)

\begin{tabular}{lccccccc}
\hline \multicolumn{7}{c}{ ACCC } \\
\cline { 1 - 5 } Identificaçáo do Grupo & $\boldsymbol{N}$ & Média & $\begin{array}{c}\text { Desvio- } \\
\text { Padráo }\end{array}$ & $\boldsymbol{g l}$ & $\boldsymbol{t}$ & $\boldsymbol{p}$ \\
\hline Grupo A & 43 & 112,98 & 8,97 & 86 & $-2,388$ &, 019 \\
\hline Grupo B & 45 & 118,38 & 11,99 & & \\
\hline
\end{tabular}

$\mathrm{n}$ - tamanho da amostra; $\mathrm{gl}$ - graus de liberdade

No que diz respeito à hipótese de que " $A$ auto-estima dos adultos que realizaram o processo de RVCC-NS difere significativamente da dos adultos que não o realizaram”, verificámos que existem diferenças significativas entre os dois grupos, uma vez que a média do grupo A foi significativamente mais baixa que a do grupo B (de acordo com os valores no quadro 5), confirmando-se a hipótese.

Quadro 5. Teste t para a auto-estima (ROS)

\begin{tabular}{lccccccc}
\hline \multicolumn{7}{c}{ ROS } \\
\hline Identificaçáo do Grupo & $\boldsymbol{N}$ & Média & $\begin{array}{c}\text { Desvio- } \\
\text { Padráo }\end{array}$ & $\boldsymbol{g l}$ & $\boldsymbol{t}$ & $\boldsymbol{p}$ \\
\hline Grupo A & 45 & 33,14 & 4,83 & 88 & $-3,693$ &, 000 \\
\hline Grupo B & 45 & 36,22 & 2,83 & 88 & \\
\hline
\end{tabular}

$\mathrm{n}$ - tamanho da amostra; $\mathrm{gl}$ - graus de liberdade

Por último, testámos se "Os adultos que realizaram o processo de RVCC-NS apresentam maior grau de satisfação com a vida do que os adultos que náo o realizaram", e como pode ser verificado no quadro 6, foram encontradas diferenças significativas entre os dois grupos, permitindo corroborar esta hipótese.

Quadro 6. Teste t para a satisfação com a vida (SWLS)

\begin{tabular}{lccccccc}
\hline \multicolumn{7}{c}{ SWLS } \\
\cline { 1 - 5 } Identificaçáo do Grupo & $\boldsymbol{N}$ & Média & $\begin{array}{c}\text { Desvio- } \\
\text { Padráo }\end{array}$ & $\boldsymbol{g l}$ & $\boldsymbol{t}$ & $\boldsymbol{p}$ \\
\hline Grupo A & 45 & 14,96 & 4,87 & 88 & $-3,184$ & \multirow{2}{*}{002} \\
\hline Grupo B & 45 & 18,13 & 4,57 & 88 & \\
\hline
\end{tabular}

$\mathrm{n}$ - tamanho da amostra; $\mathrm{gl}$ - graus de liberdade

Com o objectivo de analisarmos o padrão de relaçóes que as variáveis quantitativas estabelecem entre si, obtivemos a matriz de correlaçóes para ambos os grupos em análise (quadros 7 e 8). 
Quadro 7. Matriz de correlações das variáveis quantitativas (grupo A)

\begin{tabular}{|c|c|c|c|c|c|c|}
\hline & Idade & ROS & EAA & ACCC & SE-SDLQ & SWLS \\
\hline Idade & 1 & & & & & \\
\hline ROS &,- 102 & 1 & & & & \\
\hline EAA & , 112 & 259 & 1 & & & \\
\hline ACCC &, 054 &, $343^{*}$ &, $767^{* *}$ & 1 & & \\
\hline SE-SDLQ &,- 087 &, $413^{* *}$ &, $408^{* *}$ &, $354^{*}$ & 1 & \\
\hline SWLS &,- 170 &, $604^{* *}$ &,- 076 & 105 & 217 & 1 \\
\hline
\end{tabular}

* Correlação significativa a 0,05 (bidireccional); ** Correlação significativa a 0,01 (bidireccional)

Quadro 8. Matriz de correlaçôes das variáveis quantitativas (grupo B)

\begin{tabular}{|c|c|c|c|c|c|c|}
\hline & Idade & ROS & EAA & ACCC & SE-SDLQ & SWLS \\
\hline Idade & 1 & & & & & \\
\hline ROS &,- 033 & 1 & & & & \\
\hline EAA & ,089 &, $530^{* *}$ & 1 & & & \\
\hline ACCC &, 224 &, $420^{* *}$ &, $765^{* *}$ & 1 & & \\
\hline SE-SDLQ &, 072 & ,050 &, 236 &, $463^{* *}$ & 1 & \\
\hline SWLS &,- 063 & ,269 &, $350^{*}$ &, $\mathbf{4 7 1} 1^{* *}$ & ,499** & 1 \\
\hline
\end{tabular}

* Correlação significativa a 0,05 (bidireccional); ** Correlação significativa a 0,01 (bidireccional)

Da análise das matrizes apresentadas, verificámos alguns resultados interessantes. Começando pelo Grupo A (dos adultos inscritos para processo), podemos constatar que existe uma correlaçáo altamente significativa entre a aprendizagem autodirigida e a autoconfiança para a aprendizagem autodirigida, e entre a auto-estima, a satisfaçáo com a vida, e a auto-confiança para a aprendizagem autodirigida. Considerando o Grupo B (adultos certificados), as correlaçóes altamente significativas encontram-se entre a auto-aprendizagem e a satisfação com a vida e a auto-estima, entre a satisfação com a vida e a autoconfiança dos adultos para a aprendizagem autodirigida e o auto-conceito de competência cognitiva. Assim, em ambos os grupos existe uma correlaçáo significativa entre o auto-conceito de competência cognitiva e a auto-aprendizagem, a auto-estima e a autoconfiança para a aprendizagem autodirigida.

\section{Discussáo e Conclusáo}

Com este estudo pretendíamos, essencialmente, saber até que ponto a realização do processo de RVCC-NS revela impacto na melhoria da capacidade de auto-aprendizagem, na autoconfiança para a auto-aprendizagem, no auto-conceito de competência cognitiva, na auto-estima e na satisfação com a vida.

No que concerne à relação entre o auto-conceito de competência cognitiva e a realização do processo de RVCC-NS, encontrámos diferenças significativas $(t=-2,388 ; p=0,019)$. Uma vez concluído o processo de RVCC-NS com sucesso, não é de estranhar que os adultos tenham uma percepção mais elevada das suas competências cognitivas, implicadas 
na resolução de problemas e que revelem mais motivação e prudência na aprendizagem. De facto, pudemos verificar através de uma questão aberta ${ }^{17}$, que muitos sujeitos (cerca de 1/3) referiram que o processo de RVCC-NS permitiu aprofundar o seu auto-conhecimento e reforçou a sua capacidade para aprender. Estas observaçôes qualitativas vão ao encontro dos resultados obtidos no ACCC, que mostram que os sujeitos passaram a percepcionar-se de forma mais eficaz/competente no domínio cognitivo. Talvez, por isso, se tenha constatado, de forma muito frequente (questão aberta), a manifestação do desejo e vontade de prosseguir os estudos. Neste sentido, podemos inferir que, na sequência do impacto que o processo de RVCC-NS tem na percepção de competência cognitiva dos sujeitos, este se constitui como um veículo promotor do desenvolvimento dos sujeitos, fomentando nestes o desejo de continuar a aprender e de aumentar a sua qualificação, concretizado através da ambição em realizar acçôes de formação ou frequentar o ensino superior.

No que diz respeito às variáveis ligadas ao bem-estar pessoal - auto-estima e satisfação com a vida - os resultados foram ao encontro do esperado, validando-se as hipóteses formuladas. No primeiro caso, verificámos que os adultos que concluíram o processo de RVCC-NS apresentaram uma auto-estima significativamente mais elevada do que a dos adultos do grupo de comparaçáo $(t=-3,693 ; p=0,00)$, corroborando igualmente os resultados de estudos anteriores, nomeadamente o do CIDEC (2004) e da Universidade Católica Portuguesa/Agência Nacional para a Qualificação, I.P. (Valente et al., 2009), que revelaram que a realizaçáo do processo de RVCC produz um aumento na auto-estima dos sujeitos. É interessante verificar que, quando se perguntava, no nosso protocolo, "Quais os principais motivos por que pretende realizar o processo de RVCC?”, a resposta mais assinalada ${ }^{18}$ foi "Para elevar a minha auto-estima (ou promover o meu desenvolvimento pessoal)" e que, na questáo aberta, os próprios sujeitos identificaram o aumento da autoestima como uma das principais mudanças que sentiram com o processo de RVCC-NS, sendo essa uma das respostas mais frequentes (a par da realizaçáo e valorização pessoal), encontrando-se afirmaçóes como: "Sinto-me realizado"; "Estou orgulhoso" e "Hoje estou mais feliz comigo próprio". Assim, os nossos resultados reforçam inteiramente a conclusão de que o processo de RVCC-NS tem um impacto significativo na melhoria da auto-estima dos adultos, constituindo-se como uma fonte importante de motivação e valorizaçáo pessoal.

Associada a esta última constatação, encontra-se a satisfação com a vida, para a qual também se verificou uma mudança significativa com a realizaçáo do processo de RVCC-NS $(t=-3,184 ; p=0,02)$. Esta relaçáo pode ser explicada pelo facto de que muitos dos adultos entendem a conclusão do $12^{\circ}$ ano como um objectivo que tinha ficado por concretizar. Assim, ao ser alcançado, sentem uma maior realização/satisfação com a sua vida.

No que respeita à terceira variável do bem-estar pessoal - autoconfiança - não encontrámos diferenças significativas $(t=-0,808 ; p=0,421)$. Considerando que os processos de RVCC exigem uma elevada autonomia na construção do PRA, que por vezes, implica a pesquisa de informação ${ }^{19}$, esperávamos encontrar uma relação entre estas duas variáveis. No entanto, tal não foi verificado. A não confirmação desta hipótese, pode dever-se à última

${ }^{17} \mathrm{O}$ último ponto era uma questâo de resposta livre: "Qual lhe parece ter sido a principal mudança que o processo RVCC (Reconhecimento, Validação e Certificação de Competências) provocou em si?”

18 Do universo de 90 sujeitos, 71 assinalaram esta opção.

${ }^{19}$ De referir que o Referencial de Competências-Chave de Nível Secundário incluiu várias competências, algumas das quais são muito específicas, o que, por vezes, se reflecte na necessidade de pesquisa de informação, por parte dos adultos, com o objectivo de aprofundar os temas abordados no PRA. 
fase do processo de RVCC-NS, que consiste na realização de Formação Complementar. Durante esta fase, os adultos sáo acompanhados pelos formadores no sentido de colmatarem algumas lacunas constatadas durante a fase de Reconhecimento, quer a nível das competências que náo foram totalmente evidenciadas, quer a nível de lacunas verificadas na construção e organização do PRA. Neste sentido, podemos conjecturar que esta fase pode constituir-se como um bloqueio ao desenvolvimento da autoconfiança para a autodirecção na aprendizagem. Por este motivo, pensamos que será interessante a realização de um estudo longitudinal, que contemple um momento de avaliação antes dos sujeitos iniciarem o processo de RVCC-NS, outro antes de iniciarem a fase de Formação Complementar e outro aquando da conclusão do processo, de forma a averiguar se existem diferenças significativas na autoconfiança dos adultos ao longo das diferentes etapas do processo. Por outro lado, a inexistência de relaçáo significativa pode dever-se também a limitaçóes do plano de investigação utilizado, uma vez que é de natureza não experimental.

Outra das hipóteses confirmadas prende-se com a percepção de competência de autoaprendizagem, que se revelou significativamente superior no grupo que concluiu o processo de RVCC-NS $(t=-2,620 ; p=0,010)$. É interessante analisar os dados obtidos à luz do modelo estrutural da autodirectividade na aprendizagem, apresentado por Oliveira (2005), segundo o qual, quer as crenças epistemológicas dos sujeitos, quer a confiança pessoal ${ }^{20}$, influenciam directamente a predisposição para a autodirecção dos sujeitos. Neste sentido, e uma vez que neste estudo não se encontraram alteraçóes significativas nas crenças epistemológicas $^{21}$ dos sujeitos, é compreensível que a mudança na autodirecção dos sujeitos não seja tão substancial quanto esperada. Contudo, e segundo este modelo, o factor confiança pessoal é mais influente na autodirecção da aprendizagem. De entre as três variáveis que constituem este factor, encontrámos alteraçóes significativas na auto-estima e na satisfação com a vida, o que explica a transformação registada na autodirecção da aprendizagem destes sujeitos, mostrando que estas variáveis estão, de facto, associadas.

Neste sentido, consideramos que será interessante realizar-se um estudo de análise de impacto, que permita verificar a consistência da mudança que o processo de RVCC-NS provoca nos sujeitos. Efectivamente, no nosso estudo, os sujeitos preencheram o protocolo pouco tempo após terem obtido a sua certificação (entre 1 e 15 dias), pelo que será interessante verificar se as alteraçóes provocadas com a realização do processo de RVCC-NS tendem a ser permanentes. Com os resultados obtidos neste estudo, e à luz do modelo estrutural da autodirectividade de Oliveira (2005), podemos prever que, possivelmente, a mudança que o processo de RVCC-NS produziu na autodirecção para a aprendizagem não tenderá a ser permanente, uma vez que não verificámos diferenças significativas nas crenças epistemológicas dos sujeitos. Neste sentido, também é interessante destacar o trabalho de investigaçáo realizado por Alcoforado (2008), com adultos em processo de RVCC de Nível Básico (NB), uma vez que estudou o impacto deste processo nas variáveis auto-estima e satisfação com a vida, ao longo do tempo. Esta investigação mostrou que este processo "não revela uma influência positiva na satisfação com a vida, na medida em que o efeito principal do tempo se náo revela positivo" (p. 327), apesar de ter sugerido

\footnotetext{
${ }^{20}$ Oliveira (2005) identifica um factor designado de confiança pessoal e que é constituído pela auto-estima, autoconfiança para a aprendizagem autodirigida e satisfação com a vida.

${ }^{21} \mathrm{O}$ nosso estudo incluiu também a variável das Crenças Epistemológicas, mas por motivos relacionados com limitaçóes de espaço neste artigo, optámos pela não apresentação e discussão desses resultados.
} 
que a sua realizaçáo contribui para diferenciar o comportamento entre o grupo de sujeitos que o efectuou e o grupo de sujeitos que não o realizou. Neste mesmo estudo, e no que concerne à auto-estima, foi sustentada a hipótese de que a realização do processo de RVCC-NB provoca alteraçóes significativas nesta variável. Considerando que os processos de RVCC-NS são mais longos do que os do nível básico e que apresentam uma estrutura metodológica diferente, será interessante desenvolver um estudo que permita verificar a estabilidade na mudança destas variáveis e, por sua vez, a consistência nas mudanças produzidas na autodirecção para a aprendizagem.

Por último, não podemos deixar de referir que, o facto desta investigação se ter baseado num plano não experimental, recorrendo a um design com grupo critério, apenas nos permitiu determinar as características que estão associadas ao grupo de sujeitos que realizam os processos de RVCC-NS, indicando que, presumivelmente, a realização do processo de RVCC-NS precedeu e provocou esses comportamentos, i.e., fomentou a capacidade de autodirecçáo na aprendizagem, melhorou a auto-estima, a satisfaçáo com a vida e o autoconceito de competência cognitiva. Assim, entendemos que um estudo quase experimental com pré e pós-teste será uma boa opção metodológica para confirmar as relaçôes de causalidade propostas neste estudo.

\section{Referências Bibliográficas}

Alcoforado, J. L. M. (2008). Competências, Cidadania e Profissionalidade: limites e desafios para a construção de um modelo português de educação e formação de adultos. Dissertação de Doutoramento não publicada. Coimbra: Universidade, Faculdade de Psicologia e de Ciências da Educação.

Almeida, M., Candeias, P., Morais, E., Milagre, C., \& Lopes, G. (2008). Metodologia de Acolhimento, Diagnóstico e Encaminhamento de adultos. Lisboa: ANQ, I.P.

CIDEC (2004). O impacto do reconhecimento e certificação de competências adquiridas ao longo da vida. Lisboa: DGFV.

Comissão Europeia (2006). Educação de adultos: Nunca é tarde para aprender. Bruxelas: Comissão das Comunidades Europeias.

DGFV (2004). Reconhecimento, Validação e Certificação de Competências: Um ponto de chegada, vários pontos de partida. Aprender ao Longo da Vida, 1, 53-55.

DGFV (2005). Reconhecer, validar e certificar competências: Um passaporte para a educação e formação ao longo da vida. Formar, 50, 24-29.

Gomes, M., Umbelino, A., Martins, I. Oliveira, J., Bentes, J., \& Abrantes, P. (2006). Referencial de CompetênciasChave para a Educação e Formação de Adultos - Nivel Secundário: Guia de Operacionalização. Lisboa: Direcção Geral de Formação Vocacional.

Gomes, M., \& Simóes, F. (2007). Carta de Qualidade dos Centros Novas Oportunidades. Lisboa: Agência Nacional para a Qualificação, I.P.

IEFP (2006). Novas Oportunidades - Iniciativa no âmbito de Plano Nacional de Emprego e do Plano Tecnológico. Portugal: Ministério do Trabalho e da Solidariedade Social e Ministério da Educação.

Josso, M. C. (2001). Experiências de vida e formação - Recensão. Revista Portuguesa de Pedagogia, 35 (1), 191-195.

Knowles, M. (1998). The andragogical model: The evolution of a model of learning. In P. S. Cookson (Ed.), Program planning for the training education of adults: North American perspectives (pp. 46-56). Malabar, FL: Krieger Publishing Company.

Lima, L. C. (2007). Educação ao longo da vida: Entre a mão direita e a máo esquerda de Miró. São Paulo: Cortez Editora.

Newton, R., \& Rudestam, K. (1999). Your statistical consultant: Answers to your data analysis questions. Thousand Oaks: Sage Publications.

Oliveira, A. L. (2005). Aprendizagem Autodirigida: Um contributo para a qualidade do ensino superior. Dissertação de Doutoramento não publicada. Coimbra: Universidade, Faculdade de Psicologia e de Ciências da Educação. 
Pinho, A., Lobo, I., \& Caramujo, M. (1996). Educação de adultos: Ontem, hoje e... resenha histórica. In Actas das Jornadas de Educação de Adultos em Portugal: Situação e Perspectivas (pp. 363-368). Coimbra: Comissão Organizadora das Jornadas de Educação de Adultos.

Pires, A. (2007). Reconhecimento e validação das aprendizagens experienciais. Uma problemática educativa. Sísifo - Revista de Ciências da Educação, 2, 5-20.

Santos, N. L., \& Faria, L. (1998). Escala de Auto-Aprendizagem. Porto: Universidade, Faculdade de Psicologia e de Ciências da Educação.

Santos, N. (1999). Educação e aprendizagem de adultos: Desafios da auto-aprendizagem. Revista Portuguesa de Pedagogia, 33 (1), 45-66.

Trigo, M. (2002). Entrevista com Márcia Trigo. Saber +, 13, 10-21.

Tuckman, B. (2002). Manual de investigação em educação. Lisboa: Fundação Calouste Gulbenkian.

Valente, C., Carvalho, L., \& Carvalho, A. (2009). Estudos de Caso de Centros Novas Oportunidades. Lisboa: ANQ, I.P.

Veiga Simão, A. M., \& Flores, M. A. (2006). O aluno universitário: Aprender a auto-regular a aprendizagem sustentada por dispositivos participativos. Revista Ciências \& Letras, 40, 229-251.

\section{Legislaçâo Referenciada}

Portaria 86/2007 - Altera a Portaria 1082-A/2001, actualizando os regulamentos do Sistema Nacional de RVCC. Portaria 370/2008 - Regula a criaçáo e o funcionamento dos Centros Novas Oportunidades. 

Série Documentos

Imprensa da Universidade de Coimbra

Coimbra University Press

2011

- U

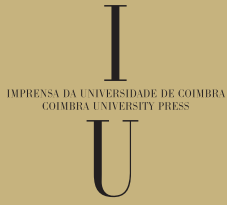

